\title{
REFLEXÕES SOBRE ATIVIDADES DE LÍNGUA PORTUGUESA ESCRITA (LPE) EM CONTEXTO DE ESCOLA BILÍNGUE PARA SURDOS
}

\author{
REFLECTIONS REGARDING THE WRITTEN PORTUGUESE LANGUAGE \\ FOR DEAF PEOPLE IN THE CONTEXT OF BILINGUAL SCHOOL
}

\author{
Josiane dos Santos Maquieira | Lattes | josianemaquieira@gmail.com \\ Universidade do Vale do Rio dos Sinos
}

Jéssica Daiane Levandovski Thewes | Lattes | jessica.levandovski@yahoo.es
Universidade do Vale do Rio dos Sinos (CAPES)

Cátia de Azevedo Fronza | Lattes | catiafronza@gmail.com

Universidade do Vale do Rio dos Sinos

\begin{abstract}
Resumo: Neste artigo, apresentam-se reflexões a partir do estudo de Maquieira (2018) ${ }^{1}$, que se voltou a atividades de língua portuguesa escrita (LPE) em sala de aula para crianças surdas, matriculadas em uma turma multisseriada de $2^{\circ}$ e $3^{\circ}$ anos do Ensino Fundamental, em escola pública bilíngue para surdos, localizada na região metropolitana de Porto Alegre/RS. Objetiva-se, com este artigo, refletir sobre atividades de LPE voltadas a alunos surdos e (re) pensar a natureza dessas propostas para que possam contribuir ainda mais para novas ofertas para o ensino e o aprendizado da(s) língua(s). Partimos de dados abordados na pesquisa de Maquieira (2018) com base em registros de observações em sala de aula, por meio de fotos e vídeos, além de relatórios descritivos. Para este artigo, serão consideradas atividades de LPE dos estudantes em foco, a partir das "Ideias para ensinar português para surdos", produzidas por Quadros e Schmiedt (2006), pois apresentam a perspectiva de ensino bilíngue para a criança surda, com vista às diferenças linguísticas e socioculturais. Para a análise, considera-se, sob a ótica de Antunes (2003, 2007, 2009), a língua como atividade que abarca o uso não somente baseado no léxico e na gramática, mas também no desenvolvimento de textos que inclui situações de interação de LPE. Entendemos que as propostas de atividades de ensino de escrita para surdos tendem a considerar a LPE como primeira língua e, para significar esse tipo de ensino, é preciso descrever ambas as línguas, numa visão comparativa/associativa para apresentar as particularidades de cada uma, situando suas respectivas funções, antes mesmo da construção das atividades de LPE em sala de aula.
\end{abstract}

Palavras-chave: Escrita. Surdos. Atividades de língua portuguesa escrita.

\footnotetext{
${ }^{1}$ Dissertação de Mestrado do Programa de Pós-Graduação em Linguística Aplicada da Unisinos.
} 
Abstract: This article presents reflections on Maquieira's (2018) research, that investigated activities of written Portuguese language (WPL) in classes for deaf children, enrolled in the $2^{\text {nd }}$ and $3^{\text {rd }}$ grades on elementary bilingual public school for the deaf, located in the metropolitan region of Porto Alegre, state of Rio Grande do Sul. The aim of this article is to reflect and (re)think about the nature of these proposals that can assist not only students in the use of the language, but also teachers in this teaching context. The data were generated from classroom observations, through photos and videos, and descriptive reports. For this article, WPL activities students produced will be considered from the material "Ideias para ensinar português para surdos" (QUADROS; SCHMIEDT, 2006), that presents the prospect of bilingual education for the deaf child, in view of linguistic and socio-cultural differences. The analysis- follows Antunes (2003, 2007, 2009), who views the language as an activity that encompasses its use of not only based on the lexicon and grammar, but also on the development of texts which includes WPL interactions. We understand that the proposed writing activities for deaf people tend to consider WPL as their first language. Thus, to achieve that kind of teaching, it is necessary to describe both languages in a comparative/associative vision to present the particularities of each one, situating its respective functions, even before the construction of WPL activities in classroom.

Keywords: Writing. Deaf. Activities for written Portuguese language.

\section{Introdução}

Ao refletir sobre as atividades de Língua Portuguesa Escrita (LPE) para surdos, com base nos estudos de Maquieira (2018), Müller (2016), Nascimento (2015), Andrade (2012) entre outros, foi possível perceber de que maneira o ensino de língua portuguesa para surdos pode ser oportunizado no Ensino Fundamental. Além disso, identificaram-se duas práticas diferentes de ensino de língua portuguesa para surdos: a) aquelas que priorizam o uso do vocabulário da LPE, como trazem Maquieira (2018) e Nascimento (2015); b) as que não visam as semelhanças e diferenças de aprendizagem dos surdos, evidenciadas também nos estudos de Müller (2016) e Andrade (2012). Diante disso, observa-se que não há uma perspectiva que valorize a Libras e favoreça o processo de aprendizagem da língua portuguesa, uma vez que o foco está no vocabulário e não no funcionamento da(s) língua(s) em uso. 
Na pesquisa de Maquieira (2018), fica evidente que as atividades desenvolvidas em sala de aula desconsiderem objetivos para além de decodificação de palavras relacionadas a fonemas e grafemas, estruturas que remetem ao som. Müller (2016) indica que os alunos surdos têm acesso a propostas de ensino que não atendem às diferenças de aprendizagem de que necessitam, indicando práticas com subsídios teóricos na educação dos surdos. Da mesma forma, Andrade (2012) chama atenção para as diferenças linguísticas entre a Língua Brasileira de Sinais (Libras) e a língua portuguesa na modalidade escrita e destaca um modelo vigente de ensino, que não trata das particularidades de cada uma das línguas utilizadas, mesmo dentro de uma abordagem de ensino considerada bilíngue para surdos. Por fim, Nascimento (2015) reforça a necessidade da abordagem bilíngue no ensino de surdos e evidencia a existência de um ensino de língua como código.

Esses e outros estudos apontam para um modo de ensino de língua portuguesa muito semelhante, em alguns aspectos, ao que é voltado aos ouvintes, de modo que vem sendo priorizada a língua portuguesa e não a Libras, que, para os surdos, deve ser a primeira língua. Em vista do exposto, Maquieira (2018), Müller (2016), Nascimento (2015) e Andrade (2012) destacam a necessidade de o ensino pautado na LPE ser uma via de acesso a práticas sociais, que compreenda o contato com diferentes gêneros discursivos significados por processos visuais. Em relação a isso, Fernandes (2006, p. 22) acrescenta que os textos destinados ao ensino/aprendizagem de surdos precisam realizar o "casamento" entre pistas imagéticas e textuais, para estimular a reflexão dos alunos e criar hipóteses que não os levem a interpretações equivocadas.

Para as reflexões do presente texto, partimos dos dados obtidos na pesquisa de Maquieira $(2018)^{2}$, realizada com base em observações em sala de aula, por meio de fotos e vídeos, além de relatórios descritivos de uma turma multisseriada de $2^{\circ}$ e $3^{\circ}$ anos do Ensino Fundamental, em uma escola da rede estadual de ensino, localizada na região metropolitana de Porto Alegre/RS. Esta pesquisa concentrou-se na análise e compreensão das atividades de LPE realizadas por cinco crianças matriculadas em uma escola que atende surdos e o objetivo é refletir sobre as atividades de LPE voltadas aos alunos surdos e (re)pensar a natureza dessas propostas para que possam contribuir ainda mais para novas ofertas, para o ensino e o aprendizado.

\footnotetext{
${ }^{2}$ Dissertação de Mestrado desenvolvida a partir da pesquisa "Educação Bilíngue para surdos: língua portuguesa e Libras nos anos iniciais do Ensino Fundamental de 9 anos”, coordenada pela professora Cátia de Azevedo Fronza, na Unisinos/Chamada MCTI/CNPQ/MEC/CAPES No 43/2013, Processo n. 407692/2013-4.
} 
Nesta discussão, são focalizadas três produções decorrentes das práticas desenvolvidas em sala de aula, as quais exemplificam atividades que predominam nos registros de escrita dos estudantes na referida pesquisa. Em vista disso, entende-se que os parâmetros utilizados para a construção das atividades não são claros, mas os professores estão empenhados em discutir sobre direções possíveis nesse contexto de ensino no qual estão inseridos.

Para a análise, adota-se a perspectiva de ensino em que a língua de sinais tem o status de primeira língua, e a língua portuguesa, na modalidade escrita, de segunda língua (FRONZA; MUCK, 2009; FERNANDES, 2006; QUADROS, 1997). Assim, consideramos que a abordagem bilíngue ratifica o respeito à individualidade, possibilita o desenvolvimento da cultura e língua próprias dos surdos, bem como a apropriação de mundo e a construção de interações sociais por meio de uma língua não alfabética, e sem a imposição da oralidade (PEREIRA, 2000). Desse modo, compreende-se que a abordagem bilíngue para surdos propicia o acesso à língua de sinais, substancialmente necessária para que se efetive a aprendizagem da segunda língua que, na modalidade escrita, tem o papel de dar acesso ao conhecimento (FRONZA; MUCK, 2012; QUADROS; KARNOPP, 2004).

Além disso, as reflexões também se valerão das "Ideias para ensinar português para alunos surdos”, de Quadros e Schmiedt (2006), por se tratar de um livro que aborda a forma bilíngue de alfabetização da criança surda com respeito às diferenças linguísticas e socioculturais. Nessa perspectiva, a língua é compreendida como fenômeno linguístico, como atividade (ANTUNES, 2009) e são consideradas as intenções comunicativas que põem os interlocutores em interação, num cenário natural com maior visibilidade, para as relações entre língua e seus contextos de uso. Para Antunes (2009, p. 21):

[...] a língua deixa de ser apenas um conjunto de signos (que tem um significado e um significante); deixa de ser apenas um conjunto de regras ou conjunto de frases gramaticais, para definir-se como um fenômeno social, como uma prática de atuação interativa, dependente da cultura de seus usuários $[\ldots]$, assumindo assim $[. .$.$] um caráter político, histórico e$ sociocultural $[\ldots]$.

Nesse sentido, o ensino da língua vai além da "decodificação" da gramática e do léxico. Considera-se que a língua é mais que um sistema e que está sujeita a diferentes regras e normas que, embora necessárias, não são suficientes. Entende-se, sob essa ótica, o poder de significar, de conferir sentido às coisas e de mediar as relações interpessoais na interação social como os maiores potenciais da língua (ANTUNES, 2009, 2007). 
Das políticas públicas existentes, será considerado o Plano Nacional da Educação (PNE) (BRASIL, 2014), em sua meta 4 e no item 4.7, no qual a oferta da educação bilíngue para surdos nas escolas deve ocorrer com a Libras como primeira língua e a língua portuguesa como segunda língua na modalidade escrita de 0 (zero) a 17 (dezessete) anos, em escolas de classes bilíngues e em escolas inclusivas. Consideram-se também os termos do Art. 22 do Decreto no 5.626, de 22 de dezembro de 2005, que regulamentam a Lei 10.436/2002 e garantem a oferta da educação bilíngue em escolas e classes bilíngues. Essa escolha foi motivada pelo fato de este ser o documento norteador da educação na época em que os dados foram gerados (2014), ou seja, que orientava as práticas pedagógicas em foco.

Isso posto, nosso próximo passo é caracterizar a educação bilíngue, de acordo com Quadros e Schmiedt (2009) e descrever a abordagem bilíngue pela ótica dos estudos de Fronza e Muck (2012), Quadros e Karnopp (2004), Pereira (2000) e Quadros (1997).

\section{Educação bilíngue e abordagem bilíngue no contexto de ensino dos surdos}

No contexto de ensino de língua escrita para surdos, há ou, pelo menos, deveria haver, duas línguas envolvidas no cotidiano das crianças (QUADROS; SCHMIEDT, 2009), para desempenhar representações que fazem parte de um contexto educacional e da vida dos surdos e compartilhar princípios em comum, apesar das diferenças de superfície entre fala e sinal (QUADROS; KARNOPP, 2004; KLIMA; BELLUGI, 1979).

Logo, a educação de surdos e a abordagem bilíngue terão, necessariamente, distinções no âmbito de suas realizações linguísticas, como aponta Antunes (2009), pois abarcam duas formas de língua que, segundo Quadros e Schmiedt (2006), envolvem diferentes modos de tornar essas línguas acessíveis às crianças surdas, uma vez que precisam do desenvolvimento de habilidades específicas para o aprendizado da Libras, considerando essa como uma língua gesto-visual que se torna necessária para o aprendizado de língua portuguesa. Na educação de surdos, considera-se a aprendizagem de duas línguas, em que a Libras poderá ser a língua de instrução, ou não, de acordo com Quadros e Schmiedt (2006), visto que as ofertas escolares variam de acordo com as diferentes ações dos diferentes contextos de cada município e de cada estado brasileiro. Isso significa que cada estado pode apresentar a proposta de ensino com a qual melhor se adaptar.

Para ampliar as ações da educação bilíngue para surdos nos diferentes contextos escolares, remetemo-nos ao conceito de letramento descrito por Lodi (2004) a partir da perspectiva de Kleiman (2005). Sob essa ótica, o letramento não pode ser considerado 
como método, alfabetização e habilidade, mas como um conjunto de práticas que envolvem o uso da língua. Essa perspectiva vai ao encontro da abordagem de Soares (2014), a qual trata das transformações semânticas da palavra letramento ao longo das últimas décadas. Essas transformações refletem o distanciamento de uma visão estruturalista para aproximar-se da visão funcional da língua. Nesse sentido, letrado não é mais visto como aquele que realiza codificações, mas quem é capaz de fazer uso da leitura e da escrita para uma prática social, tal como escrever uma mensagem, selecionar o transporte coletivo de que necessita, encomendar um lanche via aplicativo, dentre outras atividades relativas ao cotidiano. A partir de então, compreende-se que letramento "não é pura e simplesmente um conjunto de habilidades individuais; é o conjunto de práticas sociais ligadas à leitura e à escrita em que os indivíduos se envolvem em seu contexto social” (SOARES, 2014, p. 72).

Esses estudos que refletem sobre a noção de letramento e o que é ser letrado, quando relacionados ao contexto sobre o qual estamos lançando olhar, suscitam reflexões acerca de como pode ser possibilitado o ensino de LPE e o que deve ser considerado em relação ao ensino dos surdos para que se alcance o aprendizado significativo, voltado a práticas sociais.

É preciso dizer que, no Brasil, o ensino voltado aos surdos ainda é caracterizado por práticas escolares de um currículo que prioriza o português, desconsiderando as especificidades de aprendizado dos alunos, e se concentra, essencialmente, em políticas públicas de educação por meio de assimilação, como já apontavam Brasil (1997) e Quadros (1997).

Em relação a isso, destacamos, a partir do que tem sido indicado por Müller (2016), Lacerda et al. (2013), Lebedeff (2010) e Quadros e Schmiedt (2006) que:

a) a Libras é ensinada como língua de instrução e a língua portuguesa ensinada como segunda língua;

b) a Libras é ensinada como língua de instrução e a língua portuguesa como segunda língua apenas nos anos iniciais do Ensino Fundamental;

c) a língua portuguesa passa a ser língua de instrução, com a presença de intérpretes de língua de sinais nas salas de aula, sendo a língua portuguesa desenvolvida na sala de recursos;

d) a Libras é empregada como língua de instrução com o intérprete presente desde o início da escolarização;

e) a Libras é desconhecida pelo professor e a escola não tem estrutura ou recursos humanos para garantir aos alunos o direito à educação, à comunicação e à informação. 
Além das propostas supracitadas, consideram-se ainda, de acordo como Müller (2016): i) classes de educação bilíngue e ii) classes bilíngues em escolas comuns da rede regular. A primeira refere-se a vagas para alunos surdos e ouvintes, com professores bilíngues na educação infantil e nos anos iniciais do ensino fundamental e adota a Libras e a modalidade escrita da língua portuguesa como línguas de instrução utilizadas no desenvolvimento de diferentes fases do processo educativo. A segunda, por sua vez, engloba o ensino médio ou profissional, com docentes das diferentes áreas do conhecimento, cientes da singularidade linguística dos surdos, acompanhados de tradutores e intérpretes de Libras-português.

Por outro lado, na abordagem bilíngue, deve haver o acesso simultâneo da Libras e da LPE, semelhantemente ao que ocorre nas classes bilíngues em escolas comuns da rede regular, como traz Müller (2016). Entretanto, com a diferença de que, enquanto nas classes bilíngues, em escolas comuns da rede regular, a Libras e a modalidade escrita da língua portuguesa aparecem como língua de instrução, na abordagem bilíngue, só a Libras tem esse status, e a LPE é reconhecida como segunda língua, de acordo com Fronza e Muck (2012), Quadros e Karnopp (2004), Pereira (2000) e Quadros (1997). Nessa perspectiva, enfatiza-se a língua de sinais como mediadora do conhecimento, capaz de respeitar a experiência visual do surdo como constituidora de cultura singular (BRASIL, 2014). Além disso, essa abordagem permite o desenvolvimento da cultura e línguas próprias dos surdos, a apropriação de mundo e o estabelecimento de interações sociais por meio de uma língua não alfabética (PEREIRA, 2000).

Com base no exposto, tem-se a necessidade de significar o ensino de língua portuguesa para os surdos, na forma escrita, com suas funções sociais, cumprindo diferentes funções comunicativas e respondendo a um propósito que possibilite a realização de alguma atividade sócio comunicativa entre as pessoas, em relação a diversos contextos sociais em que atuam, conforme salientam Quadros e Schmiedt (2006). Afinal, é também pela escrita que alguém informa, avisa, adverte, anuncia, descreve, explica, comenta, opina argumenta, instrui, resume, documenta, faz literatura, organiza, registra, entre outros (ANTUNES, 2003).

Com base nas diretrizes dos Parâmetros Curriculares Nacionais (PCNs) ${ }^{3}$ (BRASIL, 1998), na perspectiva de gramática normativa e descritiva do ponto de vista de Bechara (2015), na concepção de ensino de língua escrita de Antunes $(2009,2007)$ e também nas experiências de pesquisa de Oliveira (2018) e Quadros e Schmiedt (2006),

\footnotetext{
${ }^{3}$ Registramos que hoje a Educação Básica se vale das orientações da Base Nacional Comum Curricular (BNCC) (BRASIL, 2018). Não consideraremos esse documento neste artigo, pelo fato de o estudo a que nos remetemos não ter se valido da BNCC, já que Maquieira (2018) não o considerou. Ressalta-se, contudo, a necessidade de as pesquisas atuais tomarem a BNCC também como uma referência para o ensino de línguas para surdos.
} 
acreditamos que é possível alcançar a significação da língua portuguesa como segunda língua para os surdos. Assim, no tópico seguinte, apresenta-se uma discussão sobre o ensino de língua portuguesa como segunda língua para os surdos, tendo em vista os referenciais supracitados.

\section{Língua portuguesa como segunda língua: a produção escrita dos surdos}

Embora os PCN's não tenham um texto voltado, propriamente, para regulamentar o ensino de língua portuguesa para surdos, eles apresentam diretrizes para o ensino da língua escrita - a segunda língua dos surdos. Nesse documento, leitura e escrita são compreendidas como práticas fortemente relacionadas. Assim, a leitura tanto fornece a matéria prima para a escrita como também contribui para a constituição de um modelo: como escrever. Dito de outro modo, significa trazer contextos de práticas com foco no uso da língua, na reflexão sobre as diferentes formas de se dizer o que se quer dizer e permitir ao aprendiz conceituar e classificar a língua (ANDRADE, 2012).

Para Bechara (2015), não se pode fazer registro e descrição de um sistema linguístico sem defini-lo, ou apenas definir o registro de um sistema linguístico numa língua funcional, estabelecendo o que é certo ou errado no nível do juízo de valor referente às conformidades do falar com o respectivo saber linguístico (elocutivo, idiomático e expressivo $)^{4}$. Para o autor, é preciso diferenciar descrição e norma de um sistema linguístico, pois a descrição ocorre em aspectos (fonético-fonológico, morfossintático e léxico), enquanto que a norma tem uma finalidade pedagógica, ou seja, recomenda “[...] como se deve falar e escrever segundo o uso e a autoridade dos escritores corretos e dos gramáticos e dicionaristas esclarecidos" (BECHARA, 2015, p. 54).

Numa concepção de língua em que a gramática se confunde com a própria língua (ANTUNES, 2007), no que se refere à língua portuguesa, há, unicamente, a constituição de componentes linguísticos no nível do léxico e da gramática. Embora estejam em íntima inter-relação (léxico e gramática), esses componentes incluem apenas regras, adaptações e especificidades morfológicas, supondo que a língua não é mais que um conjunto de palavras, vocabulário, com representação de um sistema gráfico próprio (ortografia), que ora se regula pela fonética ${ }^{5}$, ora pela fonologia ${ }^{6}$ para chegar a uma só unidade gráfica para um só valor fônico (BECHARA, 2015). Essa visão pressupõe o ensino de palavras a partir dos sons de fala, no caso da fonética, e considera a palavra funcionalmente no nível da fonologia.

\footnotetext{
${ }^{4}$ Consideram-se como saberes linguísticos, de acordo com Bechara (2015), respectivamente: elocutivo, o saber falar com congruência; idiomático, o saber fundamentado e baseado nas regras de estruturação e funcionamento da língua; e o expressivo, saber estruturar os discursos, textos para atender a diferentes e determinadas situações.

${ }^{5}$ Consideramos o que traz Bechara (2015, p. 55) de que “[...] a fonética se ocupa do aspecto acústico e fisiológico dos sons reais e concretos dos atos linguísticos: sua produção, articulação e variedades.

${ }^{6}$ No que se refere à fonologia, pode-se afirmar, segundo Bechara (2015, p.55), que esta é a unidade básica e não o som, mas o fonema, visto como unidade acústica que desempenha função linguística distintiva de unidades linguísticas superiores dotadas de significado.
} 
Contudo, e ainda de acordo com Antunes (2007), a língua também é formada por interações complexas que, necessariamente, compreendem a composição de textos (recursos de textualização) e situações de interação (normas sociais de atuação) que não se sobrepõem aos componentes: léxico e gramática. A língua "[...] é um depositário dos recortes com que cada comunidade vê o mundo, as coisas que a cercam, o sentido de tudo" (ANTUNES, 2007, p. 42).

De acordo com Antunes (2007), embora recubra diferentes funções, como unidades de sentido (tecendo a rede de significados do texto), materializando, mediando as intenções do nosso dizer, o léxico funciona como amarração de subpartes do texto, isto é, permite a atividade significativa de nossas atuações verbais. Em vista disso, entende-se que "[...] a ampliação vocabular é relevante devido às possibilidades cognitivo-comunicativas de fato, um vocabulário mais amplo constitui uma via de acesso a muitas informações [...]” (ANTUNES, 2007, p. 43).

Mesmo assim, ainda é necessário mostrar aos alunos as funções do léxico na construção de textos, procurando reconhecer contextos em que as palavras ocorrem. Do contrário, haverá uma fixação no estudo da gramática, com a crença de que esse estudo prepara suficientemente para participar ativamente das atividades de linguagem verbal (ANTUNES, 2007). No caso das crianças surdas, Quadros e Schmiedt (2006) afirmam que é preciso diversas oportunidades de uso da escrita para que esse uso sirva de base para o reconhecimento e elaboração da escrita com significado. Nesse sentido, Oliveira (2018) afirma que, quando há projetos voltados para o ensino de leitura e escrita, considerando particularidades do ambiente em que são desenvolvidos, podem oportunizar a conscientização dos alunos sobre suas necessidades linguísticas, a prática das habilidades integradas, a melhora na motivação e estimulação dos alunos e experiência significativa de ensino e aprendizagem para os discentes e docentes envolvidos.

Em relação à prática de projetos, Oliveira (2018) salienta ainda que o trabalho nessa perspectiva não focaliza o processo de ensino, mas sim a aprendizagem do aluno, além de impulsionar a motivação, envolvimento, engajamento, participação e aproveitamento dos estudantes no decorrer do processo.

Quadros e Schmiedt (2006) consideram que a compreensão dos alunos surdos da LPE também pode ser promovida por meio de discussões prévias ou estímulo visual sobre um determinado assunto. Como ocorre no trabalho com projetos, as autoras defendem a realização de discussões prévias com os aprendizes e assumem que brincadeiras e atividades que conduzam a um tema a ser desenvolvido em sala de aula, com pelo me- 
nos dois tipos de leitura, são grandes gatilhos de aprendizagem de língua. Nesse sentido, entende-se que não há diferenciação do ensino de língua portuguesa desenvolvido com ouvintes, pois, em ambos os casos, é a partir da leitura que se apreendem informações gerais de um texto, tanto para ouvintes quanto para surdos, por meio de ideias gerais ou informações mais específicas, e se atinge a motivação necessária do aluno para a leitura.

Além disso, as linguistas também sugerem atividades que possibilitem a discussão sobre palavras que aparecem no texto, estimulando, por exemplo, a busca no dicionário, conforme o nível de aprendizagem da turma, sem que haja uma preocupação exagerada com a estruturação frasal na língua portuguesa. As autoras ainda recomendam o trabalho com palavras-chave, desenvolvido em grupos ou individualmente, para garantir um registro escrito ou ilustrado como resultado do aprendiz.

As autoras ainda destacam o uso das histórias em quadrinhos como atividades significativas, uma vez que oportunizam o desenvolvimento linguístico, por meio da criação de frases relacionadas com os desenhos de uma história em sequência e, com isso, impulsionam trocas entre os colegas, por meio de diferentes versões da mesma história, ou ainda atividades de leitura em Libras e a transcrição em língua portuguesa, para comparar o texto sinalizado com o texto escrito, relacionando interpretação em Libras e a experiência com a escrita. Por fim, referimo-nos ao exercício de ordenação de frases, ou de recortes de sentenças, misturando palavras e reorganizando-as até formarem novas frases e, posteriormente, textos.

Após refletir sobre diferentes meios de significação para o ensino de língua na modalidade escrita para surdos, passamos à descrição do contexto da pesquisa no qual este artigo se concentra e, posteriormente, à discussão acerca de atividades de LPE desenvolvidas nesse contexto.

\section{Contexto de pesquisa}

Os dados a que este artigo faz referência são um recorte da pesquisa Maquieira (2018). O estudo se voltou à análise de atividades de LPE pensadas para crianças surdas, matriculadas em uma turma multisseriada de $2^{\circ}$ e $3^{\circ}$ anos do Ensino Fundamental, registradas por meio de vídeos, relatórios de observações de nove aulas de Língua Portuguesa, que ocorreram entre os meses de maio a novembro de 2014.

Conforme mencionado, tais dados fazem parte dos estudos realizados na pesquisa "Educação Bilíngue para surdos: língua portuguesa e Libras nos anos iniciais do Ensino Fundamental de 9 anos", cujo objetivo era analisar o desenvolvimento linguístico de crianças surdas quanto à aprendizagem da leitura e da escrita nos anos iniciais do Ensino 
Fundamental. A escola contava, no ano de 2014, com 64 alunos matriculados, entre as modalidades de Educação Infantil, Ensino Fundamental - Anos Iniciais e Finais e EJA. Entretanto, o estudo se deteve no acompanhamento de uma turma multisseriada, de $2^{\circ} \mathrm{e}$ $3^{\circ}$ anos, com cinco alunos, de faixa etária entre 8 e 12 anos, sendo que quatro eram surdos e um ouvinte, embora não se valesse da fala para comunicação. Todos os estudantes utilizavam a Libras para se comunicarem, ainda que o contato com a língua fosse tardio e restrito ao ambiente escolar.

No que se refere aos aspectos estruturais, vale destacar que a escola dispunha de dez salas de aula, uma biblioteca, uma sala de Artes, uma sala de Educação Física, uma Brinquedoteca e uma Diversoteca. Havia também outros espaços didáticos, como o laboratório de informática, a sala de vídeo e a cozinha experimental. Além disso, na parte externa, estavam distribuídas a horta escolar, a quadra esportiva e a pracinha.

Em 2014, a escola contava com quatorze professores, cuja formação compreendia Magistério, Graduação e Pós-Graduação, em nível de Especialização. Dos professores que haviam realizado algum curso de Especialização, a formação era voltada à Psicopedagogia e à Alfabetização. Cabe ressaltar que apenas uma das professoras era surda e atendia todos os alunos do Ensino Fundamental. Além dos professores, havia, também, oito oficineiros que desenvolviam atividades no turno inverso, pelo programa Mais Educação ${ }^{7}$.

No que diz respeito à perspectiva de ensino adotada pela escola, nota-se que, a instituição apresenta um currículo baseado em uma proposta bilíngue para o ensino de surdos. O Projeto Político Pedagógico (PPP) (2013-2015) da escola evidencia o contato com a Libras e com a LPE para "[...] o exercício da cidadania de cada aluno" e numa perspectiva de sistema de ensino de uma escola de Educação Inclusiva. Ou seja, a escola também contava com alunos com comprometimentos associados à deficiência visual ou mental, deficiência física, paralisia cerebral, entre outros, por apresentar um ensino baseado na Política Nacional de Educação Especial, que assegura o direito de todos os estudantes a estarem juntos, aprendendo e participando, sem nenhum tipo de discriminação.

No que diz respeito aos dados considerados para este artigo, destacamos que correspondem a uma das turmas da referida escola, que contava com cinco alunos, com faixa etária entre 8 e 12 anos de idade de uma turma multisseriada de $2^{\circ}$ e $3^{\circ}$ anos do Ensino fundamental. Todos os alunos faziam uso da Libras para a comunicação, embora apresentassem aquisição de Libras tardia devido ao contato restrito ao ambiente escolar.

\footnotetext{
7 Trata-se de um Programa promovido pelo Governo Federal, criado pela Portaria MEC no 1.144/2016 e regido pela Resolução FNDE no 17/2017, com a finalidade de melhorar a aprendizagem em Língua Portuguesa e Matemática no Ensino Fundamental, possibilitando aos estudantes a permanência em tempo integral na escola para o desenvolvimento de atividades também nos campos de artes, cultura, esporte e lazer, impulsionando a melhoria do desempenho escolar.
} 
A professora regente da turma tinha formação em Magistério, Graduação em Pedagogia e capacitação em Libras. Há 22 anos, atuava em sala de aula com alunos ouvintes e com alunos surdos.

Com base nos aspectos elucidados, que caracterizam a instituição, corpo docente e discentes e participantes da pesquisa, no próximo tópico, são identificadas e analisadas atividades de produção escrita dos alunos desenvolvidas no contexto da escola investigada.

\section{Atividades de Língua Portuguesa em uma escola de surdos}

No período que correspondeu à etapa de observação de nove aulas, considerando o que foi indicado por Maquieira (2018), houve propostas de atividades de leitura de diferentes gêneros discursivos e literários, como jornais e livros de histórias infantis, atividades de caça-palavras, quebra-cabeças ou construção de estruturas frasais com verbos e/ ou identificação de palavras de língua portuguesa em textos. Também foi possível acompanhar atividades de separação em sílabas, hora do conto e produções escritas. Nesse sentido, as aulas eram bem diversificadas, apresentavam objetivos diversos, e algumas delas contemplavam atividades de escrita. O Quadro 1 apresenta uma síntese de quais aspectos da língua portuguesa foram abordados nas atividades durante as aulas observadas.

Quadro 1 - Levantamento das atividades de sala de aula

\begin{tabular}{|c|c|}
\hline Tipos de Atividades & Frequência nas aulas \\
\hline Vocabulário & \multirow{3}{*}{ Mais frequência } \\
\hline Ortografia & \\
\hline Leitura & \\
\hline Descrição de imagens & \multirow{2}{*}{ Menos frequência } \\
\hline Produção textual & \\
\hline
\end{tabular}

Fonte: Elaborado pelas autoras, com base em Maquieira (2018).

De acordo com o Quadro 1, as práticas de sala de aula, no período de observação, englobaram, predominantemente, atividades voltadas ao vocabulário, ortografia e leitura. Também foram contempladas, com menos frequência, atividades voltadas à descrição de imagens e produção textual. Nesse sentido, torna-se importante aprofundarmos o olhar acerca das atividades mais ofertadas aos alunos para refletir sobre como eram desenvolvidas. 
Para tanto, ao retomarmos os dados, destacamos, conforme nossa proposta para este artigo, algumas das atividades realizadas, com o intuito de contemplar o objetivo de refletir sobre as atividades de LPE possibilitadas aos alunos surdos e, posteriormente, (re)pensar a natureza dessas propostas. Trazemos, então: a) uma atividade de separação em sílabas; b) um exercício de elaboração de frases; e c) uma proposta entendida como atividade de produção textual. Esclarecemos que, assim como na pesquisa de Maquieira (2018), não temos a pretensão de analisar o rendimento dos alunos, mas queremos lançar outro foco para as atividades, revisitando-as para identificar outras possibilidades para o ensino da LPE. Tomemos, na sequência, a proposta ilustrada pela Figura 1.

Figura 1 - Atividade de separação em sílabas

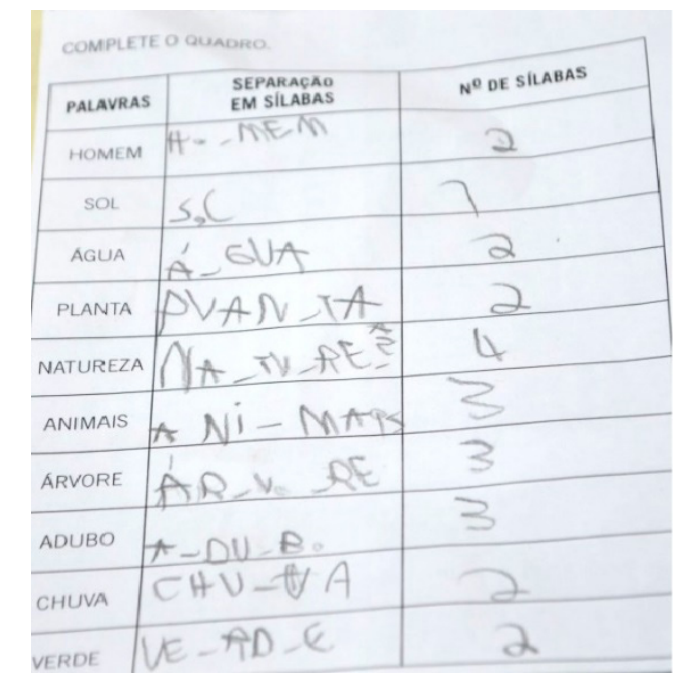

Fonte: Maquieira (2018, p. 60)

A atividade da Figura 1 está baseada no léxico da língua, de acordo com Bechara (2015), e é realizada por meio da soletração e, para dar conta da tarefa, os estudantes devem ser capazes de reconhecer a organização interna da palavra. Pode-se observar, a partir da palavra "VERDE", que uma das sílabas apresenta a separação inadequada, com a letra “R” seguida da letra "D", deixando a letra "E” separada da letra “D”. Embora as demais palavras apresentem uma correspondência com o esperado, de acordo com a gramática da LPE, tal atividade demanda conhecimentos que dependem do quanto desenvolveram sua consciência fonológica, pressupondo que os alunos percebam e compreendam a relação letra $\mathrm{x}$ fonema e como se estruturam na sílaba, como traz Fernandes (2006). No entanto, esta visão de ensino considerando letra $\mathrm{x}$ fonema pressupõe o ensino de palavras a partir dos sons, ou seja, da perspectiva ouvinte. 
Dessa forma, entendemos que, para significar o ensino de LPE, no contexto de aprendizado dos surdos, seria mais produtivo conversar com os estudantes sobre as particularidades de cada uma das línguas (QUADROS; SCHMIEDT, 2006). Isso significa deixar claro para os alunos quais as unidades mínimas da Libras formam os sinais e as suas combinações ou estruturas possíveis, como trazem Quadros e Karnopp (2004). A partir disso, mostrar que, na língua portuguesa, esse fenômeno também ocorre, por meio de padrões e combinações como as evidenciadas pelas palavras. Muito mais do que tratar da relação letra $\mathrm{x}$ fonema, haveria uma reflexão sobre o funcionamento de ambas as línguas, que poderia auxiliar a compreensão da representação da LPE.

Na Figura 2, há a atividade em que é solicitada elaboração de frases com base nas figuras e palavras sugeridas pela docente.

Figura 2 - Exercício de Elaboração de frases

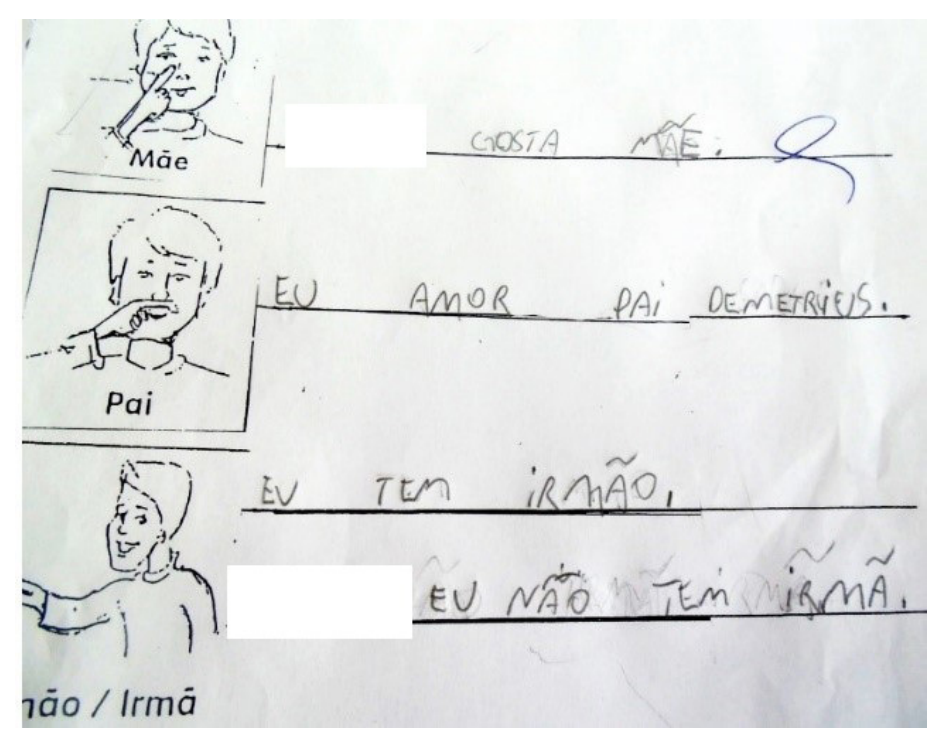

Fonte: Maquieira (2018, p. 69)

Nessa atividade, conforme mostra a Figura 2, observa-se, a partir do emprego dos verbos, um padrão de escrita diferente dos apresentados pela gramática normativa da Língua Portuguesa, destacados por Bechara (2015), no qual o saber é fundamentado e baseado nas regras de estruturação e funcionamento da LPE. Verifica-se, contudo, o uso de substantivos, verbos, pronomes pessoais e o advérbio de negação ordenadamente inseridos em cada uma das frases. Em adição a isso, observa-se que 
os verbos não apresentam a flexão de acordo com os pronomes utilizados nas três últimas frases. Na primeira, o verbo "gostar" é flexionado de acordo com o pronome pessoal "ele", representado pelo nome do participante e ocultado devido a questões éticas imbricadas à pesquisa. Na segunda frase, nota-se a presença do substantivo “amor" em lugar do verbo "amar", o qual poderia ser empregado e flexionado de acordo com a primeira pessoa do singular "eu", constituindo a sentença "Eu amo meu pai". $\mathrm{Na}$ terceira frase, esse padrão de uso permanece, no registro do verbo ter, na terceira pessoa do singular, embora use a primeira pessoa. Na última frase, também é utilizada a primeira pessoa do singular, o que caracteriza uma construção diferente das demais sentenças, com uso de pronome pessoal. Assim, nota-se que o verbo é flexionado de acordo com a terceira pessoa, a qual está representada, na frase, pelo nome próprio, porém acompanhada do pronome “eu”. Além disso, refletem, na escrita de língua portuguesa, outros padrões, típicos da Libras, como a ausência de representação específica para preposições, no caso da primeira frase, por exemplo.

Em vista do exposto, destaca-se que, nessa atividade, ou em momento anterior, não ocorreram reflexões sobre como esses padrões se estruturam nas línguas, com o foco no uso e nas diferentes formas de se dizer o que se quer dizer, como aponta Andrade (2012). Com base nesta reflexão, entendemos que atividades que levem em conta esses aspectos poderiam auxiliar os estudantes a compreenderem como a língua portuguesa escrita se constitui e, inclusive, problematizar os diferentes padrões e construções identificados. No que se refere à perspectiva de ensino de língua, dialogamos com Bechara (2015), tendo em vista a forma como a língua é trabalhada pela professora na sala de aula em foco, elucidando padrões linguísticos.

Assim, entendemos que o saber expressivo da LPE poderia contribuir nesse sentido, visto que é um saber que possibilita o reconhecimento da estruturação dos discursos, textos para atender a diferentes e determinadas situações de comunicação e, sobretudo, a necessidade de evidenciar como esse saber se constitui de modo diferente da Libras, que, nesse caso, é a língua de instrução. Isso posto, acreditamos que a inserção de diferentes contextos sociais sócio comunicativos poderiam significar a estruturação das frases, pois, como traz Antunes (2003), possibilitaria aos estudantes perceberem um propósito e direcionamento na atividade que precisaram desenvolver. 
Por fim, voltemo-nos à terceira atividade considerada neste artigo, ilustrada pela figura abaixo.

Figura 3 - Atividade de produção textual

\begin{tabular}{l} 
ALUNOS DOSTA. \\
ALUNOS TEM PEGAR. \\
\hline EU LA'PIS ESCOLA. \\
\hline PAPEL ATIVIDADES COLA. \\
\hline MESA ESAUDAR RECORTAR- \\
CADERNO SENAR CADEIRA. \\
ESGREVER.
\end{tabular}

Fonte: Maquieira (2018, p. 73 )

Nessa atividade de produção textual, assim como na anterior, identificam-se aspectos do léxico da língua portuguesa que incluem palavras, mas não incluem recursos de textualização, tais como conectores ou demais articuladores que contribuem para garantir a unidade, a harmonia ou a coerência dos textos de forma que constituam uma unidade de sentido e de intenção (ANTUNES, 2007). Dessa forma, nota-se que há conhecimento do registro e da estrutura da LPE, novamente representado pela ordenação das palavras, ainda que a construção das sentenças não esteja de acordo com os padrões normativos da língua. Contudo, não fica evidente a função social dessa escrita, bem como na atividade anterior.

Ainda em relação à atividade representada na Figura 3, vale ressaltar que, na ocasião, a docente orientou os estudantes a produzirem uma história baseada em uma imagem entregue a eles em uma folha impressa. A referida imagem, conforme pode-se observar na Figura 4, representa três crianças sentadas à mesa.

Figura 4 - Imagem para produção de texto

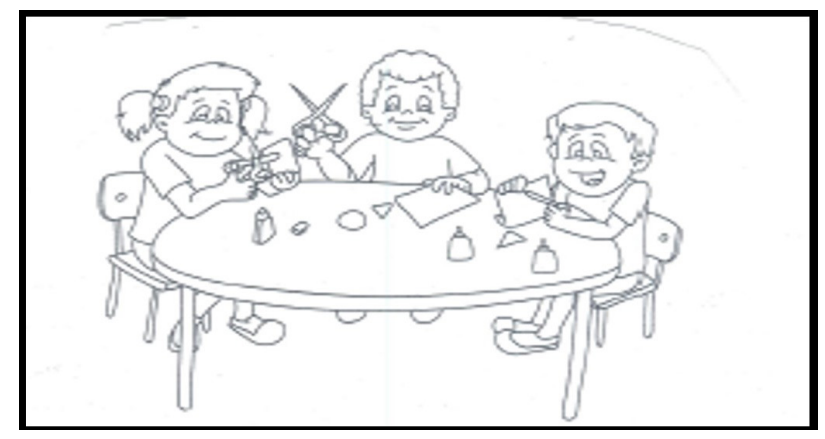

Fonte: Maquieira (2018, p. 73) 
Depois de apresentar a imagem, a docente perguntou aos alunos se viam algo representado que se assemelhasse a eles e pediu que se comparassem às crianças do desenho por meio de texto escrito. Ela também explicou que a atividade deveria ser realizada individualmente, que poderiam consultar as figuras e as letras disponibilizadas na parede da sala de aula e coladas abaixo do quadro, conforme Figura 5.

Figura 5 - Material de consulta para escrita dos alunos

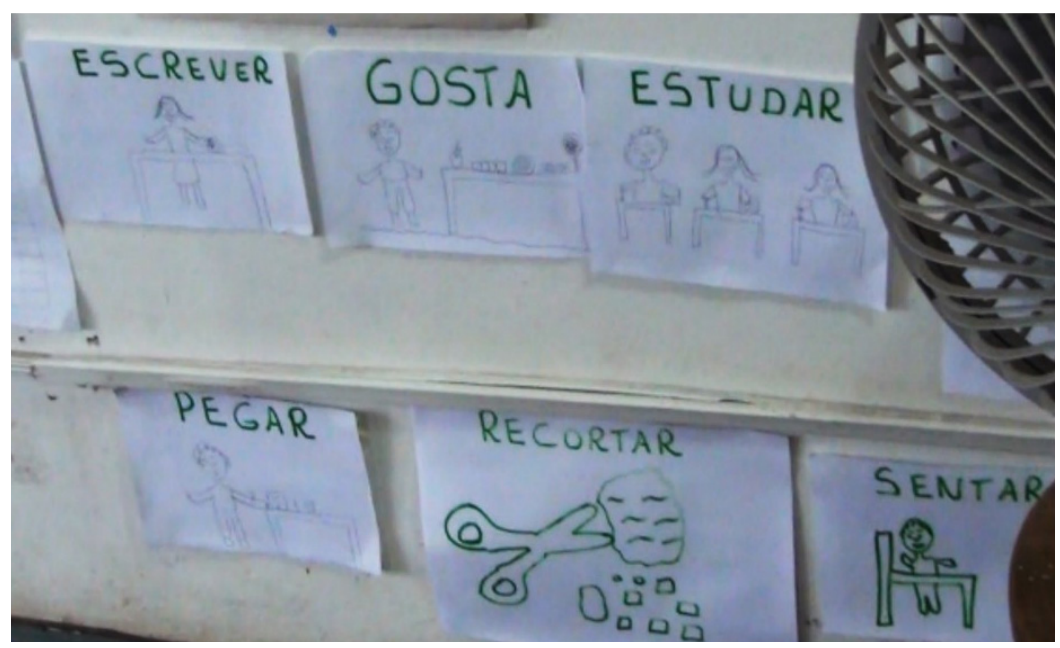

Fonte: Acervo da pesquisa (2014).

Em Libras, a professora pediu aos alunos que sinalizassem o que observaram nos desenhos. Eles sinalizaram as palavras CRIANÇA, QUADRO, MESA, TESOURA, APAGAR, ESCREVER E SENTAR. Em seguida, os alunos começaram a escrever, valendo-se das palavras das folhas afixadas, como vemos na Figura 5.

A partir da perspectiva de letrado, trazida por Kleiman (2005), e de letramento, compreendido por Soares $(2014$, p. 72$)$ como prática social, em relação à análise das atividades de língua portuguesa discutidas até aqui, entendemos que: a) é preciso explicar aos alunos como as estruturas da LPE são organizadas pela gramática, b) mostrar o sistema linguístico e seu funcionamento e c) refletir sobre os usos das construções linguísticas com finalidades específicas, por meio do contato com diversos tipos de texto, com foco na atuação em diferentes contextos sociais. Dessa forma, compreendemos que o trabalho com textos diversificados, com a Libras orientando e explicitando como esses textos são organizados e produzidos, oferece subsídios para a escrita, conforme salientado por Andrade (2012): oferecem-se modelos aos alunos sobre o que escrever e como escrever em diferentes situações de escrita da língua portuguesa no cotidiano dos alunos surdos. 
A partir das reflexões tencionadas na presente seção, ressaltamos que este texto não se propôs a esgotar as discussões a respeito das práticas de ensino de língua portuguesa para surdos. Assim, nosso foco se constituiu de mostrar as práticas já existentes e refletir a respeito de como se constituem, em um contexto escolar específico, para pensar em estratégias de aprendizagem que possam ser significativas nessa realidade escolar. Tendo em vista esses aspectos das atividades de escrita apresentadas, trazemos nossas últimas ponderações no tópico seguinte.

\section{Considerações finais}

Em vista do exposto e como considerações finais acerca deste artigo, nota-se que o presente texto partiu das reflexões realizadas por Maquieira (2018) para aprofundar as discussões sobre as atividades de LPE em um contexto específico de escola de surdos. Para tanto, buscou-se refletir sobre atividades de LPE voltadas a alunos surdos e (re)pensar a natureza dessas propostas para que possam contribuir ainda mais para novas ofertas para o ensino e o aprendizado. Assim, constatou-se nos dados uma proposta de trabalho de língua portuguesa centrada no vocabulário da língua escrita, em que língua e gramática apresentam-se como uma coisa só, como aponta Antunes (2007), e o ensino de palavras a partir dos sons de fala é bem recorrente. Também foi possível identificar que as atividades analisadas têm como base, principalmente, a norma, pois sua finalidade pedagógica é a constituição de componentes linguísticos no nível do léxico e da gramática. É preciso destacar, contudo, que a língua se constitui por meio de interações diversas que se valem de recursos de textualização e de situações de interação que não se sobrepõem ao léxico e às normas, mas, sem considerar tais relações interativas e interacionais, conhecer e usar a língua com sentido pode ser uma meta de difícil alcance.

Nessa perspectiva, compreendemos que as atividades supracitadas (atividade de separação em sílabas, de elaboração de frases e de produção textual) foram formuladas sem levar em conta a diferenciação do ensino de língua portuguesa desenvolvido com ouvintes, pois não se consideram contextos representativos, nos quais os alunos surdos pudessem perceber como as expressões presentes nas atividades ocorrem nas práticas de letramento do cotidiano. Acreditamos, portanto, no contato e nas práticas com diferentes tipos de texto, que contemplem reflexões acerca de suas especificidades e finalidades, como um caminho possível para o maior conhecimento do uso da língua, bem como de sua estrutura, tendo em vista que essas foram dificuldades apresentadas nas atividades desenvolvidas pelos estudantes. 
Se essas práticas fossem consideradas no atual momento de isolamento e distanciamento que estamos enfrentando devido à pandemia causada pela COVID-19, com os estudantes em casa participando de aulas remotas, por exemplo, poderiam ser desenvolvidas por meio do letramento digital, em que os estudantes pudessem manipular jogos educacionais, explorar plataformas de aula online, acessar livros e vídeos de narrativas digitais e também interagir por meio de diferentes gêneros que circulam nesses contextos. Dessa forma, cercados de diferentes gêneros, entende-se que as atividades impulsionam os estudantes a agirem socialmente, por englobarem processos pedagógicos que consideram situações de interação voltadas ao meio social no qual o aprendiz está inserido (FERNANDES, 2013, 2006; DIDÓ, 2012). Vale ressaltar que isso se aplica tanto para a aprendizagem da língua de instrução como da segunda língua.

Esse estudo revelou que, na escola para surdos focalizada, cuja perspectiva é direcionada para a educação bilíngue, considerando a Libras como língua de instrução, a abordagem segue acompanhada da oralidade. Entretanto, para além do exposto, problematizamos as atividades desenvolvidas, no sentido de refletir sobre o fato de contemplarem aspectos inerentes à oralidade, como é o caso da separação de sílabas. Nesse sentido, atentamos para o fato de o aluno surdo não ter essa referência para a realização do exercício, uma vez que sua língua materna - a Libras - configura-se como gesto-visual.

Além disso, também se observa que a aprendizagem da segunda língua, na modalidade escrita, tem o papel de dar acesso ao conhecimento das regras de estruturação de LPE. Em vista disso, compreendemos que associações entre as duas línguas na prática pedagógica impulsionaria a compreensão das suas especificidades e a atuação dos alunos nos dois contextos linguísticos - de uso da Libras e da língua portuguesa. Acreditamos que a perspectiva adotada pela escola esteja diretamente relacionada a uma proposta de ensino de classes bilíngues, na qual as duas modalidades (gesto-visual e escrita) aparecem como língua de instrução.

A partir do acompanhamento dessas práticas, ressaltamos ainda que, por um lado, entendemos que há a preocupação com o ensino de LPE para que o aluno possa se inserir no mundo, ainda que isso se efetive por meio de atividades que não se constituem voltadas a contextos reais de uso; por outro lado, identificamos a ausência de reflexões e práticas, em sala de aula, voltadas à Libras, língua materna dos estudantes. Em relação a isso, salientamos que a língua de instrução deve ser priorizada nas práticas de ensino, principalmente se considerarmos que muitos alunos têm o primeiro contato com a Libras apenas na escola. 
A partir das discussões tecidas no presente artigo e no conhecimento do contexto em que ocorrem as práticas pedagógicas elucidadas, entendemos que a pesquisa do ensino da Libras como língua prioritária ainda é um campo com muitas possibilidades para novos estudos, principalmente se considerado o fato de que, apesar de adquirir reconhecimento em 2002, por meio da Lei No 10.436, de 24 de abril, há necessidade de mais pesquisas voltadas a práticas de ensino da língua tanto na escola como fora dela, bem como de língua portuguesa para surdos. Vale considerar, portanto, a necessidade de investigar, por exemplo, quais são os materiais de apoio que já existem e que se encontram disponíveis para os professores que atuam com alunos surdos, bem como as formações ou outros programas ofertados para que se qualifiquem a fim de promover um ensino mais significativo para os estudantes.

Entendemos que é oportuno mencionar que dados recentes, ainda em processo de geração e análise, a partir de conversas com professores nesta e em outras escolas de surdos $^{8}$, revelam desafios que os docentes encontram para que se efetive o ensino de qualidade como, por exemplo, falta de diretrizes legais e de materiais específicos para esse público, mudanças constantes dos documentos que regulamentam a educação brasileira e a ausência de direcionamento para implementar as novas políticas na escola.

Outro aspecto a ser ponderado em relação ao ensino descontextualizado é que não deixa de ser uma característica que permeia também a realidade de escolas de ensino para ouvintes. Uma saída para este tipo de relação de ensino descontextualizado pode estar ligada aos estudos sobre letramento, considerando práticas que valorizem a cultura trazida pelos alunos, pois o ensino de uma língua supõe a aproximação com diferentes culturas, bem como reflexões para entender determinadas realidades e contextos para, então, poder atuar sobre eles, como se observa nos estudos de Rojo (2009). Para tanto, acreditamos que o ponto de partida deve ser possibilitar aos alunos a compreensão do próprio contexto em que estiverem inseridos e de como a interação acontece para que seja possível reconhecer o potencial de cada língua a que estão sendo expostos, para que percebam em maior medida, o tipo de inserção e atuação que precisam ter no mundo.

Por fim, consideramos que, nos projetos de ensino, como traz Oliveira (2018), tem-se a possibilidade de trabalhar algumas particularidades do ambiente em que são desenvolvidas as práticas de ensino e oportunizar a conscientização dos estudantes sobre suas necessidades linguísticas a serem trabalhadas.

\footnotetext{
${ }^{8}$ Os dados gerados por meio de conversas com professores, gravadas em áudio, entre os meses de fevereiro e setembro de 2018, são oriundos da pesquisa "Línguas orais e línguas de sinais: desafios e potencialidades na educação de surdos", cujo objetivo é analisar as propostas de ensino adotadas em duas escolas para surdos da região metropolitana com ênfase para o ensino de Libras e língua portuguesa escrita como segunda língua. A pesquisa possui apoio da FAPERGS, Edital 02/2017, coordenada pela profa. Dra. Cátia de Azevedo Fronza. O projeto foi aprovado pelo comitê de ética da Universidade do Vale do Rio dos Sinos (UNISINOS) conforme CAAE: 79451817.6.0000.5344.
} 


\section{Referências}

ANDRADE, M. M. Práticas de ensino da língua portuguesa para alunos surdos. 2012. 86 f. Dissertação (Mestrado em Educação) - Curso de Pós-graduação em Educação, Universidade Metodista de Piracicaba, São Paulo, 2012.

ANTUNES, I. Aula de Português: encontro e interação. São Paulo: Parábola Editorial, 2003. . Muito além da gramática: por um ensino de línguas sem pedras no caminho. São Paulo: Parábola Editorial, 2007.

. Lingua, texto e ensino: outra escola possível. São Paulo:

Parábola Editorial, 2009.

BECHARA, E. B. Moderna Gramática portuguesa. 38. ed. Rio de Janeiro: Nova Fronteira, 2015.

BRASIL. Decreto $n^{\circ}$ 5626, de 22 de dezembro de 2005. Regulamenta a Lei No 10.436, de 24 de abril de 2002, dispõe sobre a Língua Brasileira de Sinais - Libras e o art. 18 da Lei $N^{o} 10.098$, de 19 de dezembro de 2000. Disponível em: http://www.planalto.gov.br/ ccivil_03/_ato2004-2006/2005/decreto/d5626.htm. Acesso em: 09 nov. 2017.

BRASIL. Ministério da Educação. Secretaria da Educação Básica. Parâmetros Curriculares Nacionais. Brasília: MEC/SEB, 1997.

BRASIL. Ministério da Educação. Secretaria de Alfabetização e Diversidade. Secretaria de Educação Especial. Política Nacional de Educação Especial na perspectiva de educação inclusiva. Brasília: MEC/SEESP 2014a. Disponível em: http://portal.mec.gov.br/ index.php?option $=$ com_docman $\& v i e w=$ download $\&$ alias $=16690$-politica-nacional de-educacao-especial-na-perspectiva-da-educacao-inclusiva-05122014\&category_ slug=dezembro-2014-pdf\&Itemid=30192. Acesso em: 06 ago. 2018.

DIDÓ, A. G. Pareceres descritivos de alunos surdos: revelações sobre seu desempenho em língua portuguesa no ensino fundamental. 2012. 137 f. Dissertação (Mestrado em Linguística Aplicada) Programa de Pós-Graduação em Linguística Aplicada, Universidade do Vale do Rio dos Sinos, São Leopoldo, 2012.

FERNANDES, S. Práticas de letramento na educação bilíngue para surdos. Curitiba, 2006. Disponível em: http://www8.pr.gov.br/portals/portal/institucional/dee/praticas_ letramentos.pdf. Acesso em: 28 abril. 2018.

FERNANDES, S. Educação bilíngue para surdos: identidades, diferenças, contradições e mistérios. 2003. 213f Tese (Doutorado em Letras) - Setor de Ciências Humanas, Letras e Artes da Universidade Federal do Paraná, Curitiba, 2003. Disponível em: https:// acervodigital.ufpr.br/bitstream/handle/1884/24287/T\%20-\%20FERNANDES,\%20 SUELI\%20DE\%20FATIMA\%20.pdf?sequence=1. Acesso em: 05 ago. 2018.

FRONZA, C. A.; MUCK, G. F. In: LOPES, M. C. (Org.). Cultura Surda \& Libras. São Leopoldo, 2012. v. Ed. P. 47- 62.

KLEMAN, Ângela B. Preciso ensinar letramento? Não basta ensinar a ler e a escrever? São 
Paulo, Unicamp. 2005.

LACERDA, C. B. F.; ALBRES, N. A.; DRAGO, S. L. S. Política para uma educação bilíngue e inclusiva a alunos surdos no município de São Paulo. São Paulo.2013. Disponível em: http://www.scielo.br/pdf/ep/v39n1/v39n1a05.pdf. Acesso em 02 fev. 2020.

LEBEDEFF, T. B. A educação dos surdos na região do planalto médio rio-grandense: uma problematização das condições linguísticas e de escolarização. In: REUNIÃO ANUAL DA ANPED, 33., 2010, Caxambú. Anais... Rio de Janeiro: ANPED, 2010.

LEBEDEFF, T. B. O povo do olho: uma discussão sobre a experiência visual e surdez. In: LEBEDEFF, Tatiana Bolivar et al., (Org.). Letramento visual e surdez. Rio de Janeiro: Wak, 2017. p. 68-90.

LODI, A. C. B. A leitura como espaço discursivo de construção de sentidos: Oficinas com surdos. 2004. 263 f. 263 f. Tese (Doutorado) - Programa de estudos Pós-graduados em Linguística Aplicada e Estudos de Linguagem, Pontifícia Universidade Católica de São Paulo, (PUCSP), São Paulo, 2004. Disponível em: https://sapientia.pucsp.br/handle/ handle/13914. Acesso em 01 set. 2018.

MAQUIEIRA,J.S. Lingua Portuguesa Para Surdos Nos Anos Iniciais Do Ensino Fundamental: Reflexões sobre atividades em sala de aula. 2018.92 f. Dissertação (Mestrado em Linguística Aplicada) - Curso de Programa de Pós-graduação em Linguística Aplicada, Universidade do Vale dos Sinos, São Leopoldo, 2018. Disponível em: http://www.repositorio.jesuita. org.br/handle/UNISINOS/7454. Acesso em 27 abril. 2019.

MUCK, G. F. O status da Libras e da língua portuguesa em contextos de ensino e de aprendizagem de crianças surdas. 2009. 155 f. Dissertação (Mestrado em Linguística Aplicada) Curso de Programa de Pós-graduação em Linguística Aplicada, Universidade do Vale dos Sinos, São Leopoldo, 2009. Disponível em: http://www.repositorio.jesuita. org.br/bitstream/handle/UNISINOS/2584/GiseleMuckLinguisticaAplicada. pdf? sequence $=1$ \&isAllowed=y. Acesso em: 29 nov. 2017.

MÜLLER, J. I. Língua Portuguesa na educação escolar bilíngue de surdos. 2016. 295 f. Tese (Doutorado em Educação) - Curso de Programa de Pós-graduação em Educação, Universidade Federal do Rio Grande do Sul, Porto Alegre, 2016. Disponível em: http:/ / www.lume.ufrgs.br/bitstream/handle/10183/149088/001004823.pdf sequence $=1$. Acesso em: 29 nov. 2017.

NASCIMENTO, R. O. Análise de atividades de Alfabetização de estudantes surdos. 2015. 101 f. Dissertação (Mestrado em Educação) - Curso de Programa de Pós-Graduação em Educação, Universidade do Vale do Sapucaí (UNIVAS), Pouso Alegre, 2015. Disponível em: http://www.univas.edu.br/me/docs/dissertacoes2/21.pdf. Acesso em: 29 nov. 2017.

OLIVEIRA, T. C. B. C. A escrita do aluno surdo: interface entre a Libras e a língua Portuguesa. 2009. 329 f. Tese (Doutorado Educação) - Curso de Programa de Pós-graduação em Educação, Universidade Federal da Bahia (UFBA), Salvador, 2009. Disponível em: https://repositorio.ufba.br/ri/handle/ri/11066. Acesso em: 13 jun. 2020. 
OLIVEIRA, A. O. A. Projetos como metodologia de língua inglesa para surdos. $2018.103 \mathrm{f}$. Trabalho de Conclusão de Curso (Monografia em Letras) - Faculdade de Licenciatura em Letras - Inglês, Universidade do Vale do Rio dos Sinos, São Leopoldo, 2018.

PEREIRA, M. C. C. Aquisição da Língua Portuguesa por aprendizes surdos. In: 1 Seminário Desafios para o próximo milênio, 2000, Rio de Janeiro. Anais... Rio de Janeiro: INES, 2000.p. $95-100$

QUADROS, R. M. A educação de surdos: a aquisição da linguagem. ed. Porto Alegre: Artmed, 1997.

QUADROS, R.; SCHMIEDT, M. L. P. Ideias para ensinar português para surdos. Brasília, 2006. Disponível em: http://www.conhecer.org.br/download/ATENDIMENTO AO ALUNO ESPECIAL/leitura 5.pdf. Acesso em: 8 ago. 2016.

QUADROS, R. M.; KARNOPP, L. B. Lingua de sinais brasileira: estudos linguísticos. ed. Porto Alegre. Artmed, 2004.

ROJO, R. Letramentos Múltiplos, escola e inclusão social. 1. ed. São Paulo. Parábola, 2009. SOARES, M. Letramento: um tema em três gêneros. 3. Ed. Belo Horizonte: Autêntica Editora, 2014. 